Int. J. Electrochem. Sci., 14 (2019) 5899 - 5912

\title{
Facile Synthesis of Conducting Hydrogels Based on Polyaniline Fiber and Graphene Oxide for Application in all-solid-state Supercapacitors
}

\author{
Guizhen Guo ${ }^{1}$, Youyi Sun ${ }^{1,2, *}$,Yibing Ma ${ }^{1}$,Yaya Zhou ${ }^{1}$, Zhiyuan Xiong ${ }^{2}$, Yaqing Liu $^{1}$ \\ ${ }^{1}$ Shanxi Province Key Laboratory of Functional Nanocomposites, North University of China, Taiyuan \\ 030051, P.R. China. \\ ${ }^{2}$ Department of Chemical and Bio-molecular Engineering, The University of Melbourne, Victoria \\ 3010, Australia. \\ *E-mail: syyi@pku.edu.cn
}

doi: $10.20964 / 2019.06 .220$

Received: 1 November 2018 / Accepted: 31 December 2018 / Published: 10 May 2019

\begin{abstract}
A new conducting hydrogel based on graphene oxide (GO) and polyaniline (PANi) fibers was facile synthesized (denoted as GO/SA/PANi) for application in flexible all-solid-state supercapacitor device. Taking advantage of the synergistic effects of the components and synthesis strategies, the conducting hydrogels showed high mechanical stability and conductivity $(16.8 \mathrm{~S} / \mathrm{m})$. Furthermore, the supercapacitor based on GO/SA/PANi exhibited high area specific capacitance $\left(2.3 \mathrm{~F} / \mathrm{cm}^{2}\right.$ at 0.5 $\mathrm{mA} / \mathrm{cm}^{2}$ ). This study not only represents a novel conducting hydrogel for application in all-solid-state supercapacitor with high performance, but also provides a new method for enhancing capacitance and mechanical stability of conducting hydrogels.
\end{abstract}

Keywords: GO/SA/PANi; in-situ polymerization; macromolecular interaction; conducting hydrogel; supercapacitor

\section{$\underline{\text { FULL TEXT }}$}

(C) 2019 The Authors. Published by ESG (www.electrochemsci.org). This article is an open access article distributed under the terms and conditions of the Creative Commons Attribution license (http://creativecommons.org/licenses/by/4.0/). 